\title{
Differential measurement of small and large bowel transit times in constipation and diarrhoea: A new approach ${ }^{1}$
}

\author{
SHEILA L. WALLER
}

From the MRC Gastroenterology Unit, Central Middlesex Hospital, Acton Lane, London

SUMMARY Differential measurements of small and large bowel transit times were performed in 13 subjects with a radiotelemetering pressure-sensitive capsule incorporating less than $10 \mu \mathrm{Ci}$ of ${ }^{51} \mathrm{Cr}$. Six patients had constipation. The other seven patients had diarrhoea due to the irritable bowel syndrome (3), following vagotomy and pyloroplasty (3), or due to laxative abuse (1). This new method enables the gastric, small intestinal, and colonic transit times to be measured differentially in the same subject. The capsule can be localized in the gut lumen by reference to the characteristic pressure pattern and in relation to bony landmarks by the radioactive marker as frequently as desired without recourse to radiographs.

The results show that gastric emptying and small intestinal transit did not differ in constipaation and diarrhoea. By contrast the mean colonic transit was significantly faster $(\mathbf{P}<0.01)$ in diarrhoea whatever the cause $(17 \cdot 5 \pm 4 \cdot 1$ hours) than in constipation (118 $\pm 4 \cdot 1$ hours).

The differential measurement of small and large bowel transit times is important in the investigation of the mechanisms underlying diarrhoea and constipation. Moreover, the pattern of transit of colonic contents is likely to be relevant to the pathogenesis of diverticular disease and carcinoma of the colon. Unfortunately most available methods do not measure transit rates separately through the small and large intestine. Barium, for example, cannot be quantitated, alters transit time (Alvarez and Freedlander, 1924), and involves the use of $x$ rays. Radioopaque pellets (Hinton, LennardJones, and Young, 1969) do not affect intestinal function and are eminently suitable for total (mouth-to-anus) transit time, but they cannot be used to study small intestinal propulsive activity, whilst the radiation hazard severely limits their use for monitoring movements of colonic contents. Perspex spheres containing ${ }^{51} \mathrm{Cr}$ and pressuresensitive radiotelemetering capsules move similarly to radioopaque pellets in the intestine (Holdstock, Misiewicz, Smith, and Rowlands, 1970) but the necessity for $x$-ray localization makes them unsuitable for differential measurements. However, a small amount of ${ }^{51} \mathrm{Cr}$ incorporated into the radiotelemetering capsule makes it possible to chart its

\footnotetext{
${ }^{1}$ Presented in part at the meeting of the British Society of Gastroenterology, London, in September 1973. Data included in this paper forms part of thesis to be submitted for MD (Lond).

Received for publication 5 March 1975.
}

position in relation to the patient's bony landmarks with a collimated scintillation counter (Misiewicz, Waller, Kiley, and Horton, 1969). At the same time its location within the gut lumen can be determined from the characteristics of the pressure record because there are distinct pressure patterns in the stomach, jejunum, ileum, and colon (Misiewicz, Waller, Fox, Goldsmith, and Hunt, 1968). The capsule can therefore be located as frequently as required without recourse to $x$ rays.

The value of this method for measuring differential small and large bowel transit has been studied in 13 patients with diarrhoea or constipation.

\section{Methods}

Patients were ambulant throughout the test and took no medicines in the three days before and during the study. One patient, however, was a laxative abuser who presumably continued to take purgatives secretly. Meals were taken seated at a table in the laboratory. Apart from a standard breakfast at 09.00 hours, consisting of fruit, egg, toast, and two cups of tea, the patients ate the normal ward diet. Fluid intake was recorded on the first day and was maintained at the same level during the rest of the test.

The radiotelemetering capsule containing a disc of filter paper impregnated with 5 to $10 \mu \mathrm{Ci}$ of ${ }^{51} \mathrm{Cr}$ (Misiewicz et al, 1969) was given to the fasting 
patient just before, and 25 radioopaque pellets during, the standard breakfast.

The position of the capsule was plotted with the patient lying supine at intervals between 09.00 and 19.00 to 21.00 hours daily. Plots were made every 15 to 20 minutes for the stomach and small intestine and every 30 to 60 minutes for the colon. Each plot was made on a perspex sheet marked with the bony landmarks and placed on the patient's abdomen: the capsule was located to within a $5 \mathrm{~cm}$ diameter circle with a collimated scintillation counter (Ekco Electronics N559C) coupled to a ratemeter (Ekco Electronics N522C) by finding the point of maximal activity. This commercial collimated scintillation counter was awkward to handle and was later replaced by a hand-held model specifically designed for the purpose by $\mathrm{Dr} \mathrm{T}$. Smith. The positions of the capsule at the time of reading were marked on the perspex sheet and later transferred to graph paper for a permanent record. Intraluminal pressures were then recorded for about three minutes, as described previously (Rowlands and Wolff, 1960; Connell, McCall, Misiewicz, and Rowlands, 1963; Misiewicz, Waller, and Eisner, 1966) in order to determine the location of the capsule in the gut lumen (Misiewicz et al, 1968). The position of the capsule in relation to bony landmarks was plotted again after the pressure record was completed. Each plot took about five minutes. Localizations of the capsule by its radioactive emissions continued until it was eliminated in the stool, but in constipated subjects the telemetered pressure record ceased after three or four days in the colon due to battery failure. Gastric emptying time was measured from the time the capsule was swallowed to the first appearance of an upper intestinal pressure pattern. Small intestinal transit was timed until pressure activity typical of the colon was recorded; localization by the radioactive source was then in the right iliac fossa.

The rate of elimination of the radioopaque pellets was determined by fluoroscopy of the stools throughout the study.

Repeat studies were carried out in six patients who were given senna, codeine, metoclopramide, or no therapy at some stage during the second study.

For the purpose of the present study the part of the left colon below the iliac crest is designated as the 'sigmoid colon'.

\section{Results}

\section{NO TREATMENT}

Thirteen patients were studied, whose clinical details are in table I. Four had simple constipation and two constipation associated with the irritable bowel syndrome (Waller and Misiewicz, 1969); all had symptoms at the time of study. The other seven patients had diarrhoea: three due to the irritable bowel syndrome, three following vagotomy and pyloroplasty, and one was a secret laxative taker. No patient had diarrhoea alternating with constipation. Symptoms in the diarrhoeal subjects were either intermittent or continuous, but were present in all at the time of study.

The rates of gastric emptying of the capsule and the small intestinal and colonic transit times are shown in figure 1. Gastric emptying and small intestinal transit were similar in both the constipated and the diarrhoeal subjects. In all except two

\begin{tabular}{|c|c|c|c|c|c|c|c|}
\hline \multirow[t]{2}{*}{ Patient } & \multirow[t]{2}{*}{$\operatorname{Sex}$} & \multirow[t]{2}{*}{ Age } & \multirow[t]{2}{*}{ Diagnosis } & \multirow{2}{*}{$\begin{array}{l}\text { Length of } \\
\text { History (years) }\end{array}$} & \multicolumn{2}{|l|}{ Stools } & \multirow[t]{2}{*}{ Symptoms } \\
\hline & & & & & Frequency & Consistency & \\
\hline 1 & $\mathbf{M}$ & 48 & $\begin{array}{l}\text { Postvagotomy and pyloroplasty diarrhoea } \\
\text { (irritable bowel syndrome before operation) }\end{array}$ & 19 & $>3 /$ day & Watery & Intermittent \\
\hline 2 & $\mathbf{M}$ & 39 & Postvagotomy and pyloroplasty diarrhoea & 0.7 & Up to $16 /$ day & Fluid & Continuous \\
\hline 3 & $\mathbf{M}$ & 42 & $\begin{array}{l}\text { Postvagotomy and pyloroplasty diarrhoea } \\
\text { (irritable bowel syndrome before operation) }\end{array}$ & $3+$ & $2-6 /$ day & Watery & Continuous \\
\hline 4 & $\mathbf{M}$ & 30 & Irritable bowel syndrome & 5 & $2-15 /$ day & Watery & Intermittent \\
\hline 5 & $\mathbf{F}$ & 27 & Irritable bowel syndrome & 5 & $>3 /$ day & Soft or fluid & Intermittent \\
\hline 6 & $\mathbf{F}$ & 56 & Irritable bowel syndrome & 13 & $>3 /$ day & $\begin{array}{l}\text { Semi-solid or } \\
\text { fluid }\end{array}$ & Continuous \\
\hline 7 & $\mathbf{F}$ & 27 & Laxative addict & 2 & $>3 /$ day & Watery & Continuous \\
\hline \multicolumn{8}{|c|}{ Constipation } \\
\hline 8 & $\mathbf{M}$ & 40 & Simple constipation & 13 & $1 /$ week & Small pieces & Continuous \\
\hline 9 & $\mathbf{F}$ & 39 & Simple constipation & 8 & 1 every $3-4$ days & Hard & Continuous \\
\hline 10 & $\mathbf{F}$ & 56 & Simple constipation & Not noted & $1-3 /$ day & Small and firm & Continuous \\
\hline 12 & $\mathbf{M}$ & 56 & Irritable bowel syndrome & 9 & $<$ Every 3rd day & $\begin{array}{l}\text { Small pieces or } \\
\text { hard }\end{array}$ & Continuous \\
\hline 13 & $\mathbf{F}$ & 36 & $\begin{array}{l}\text { Irritable bowel syndrome (followed } \\
\text { operation for endometriosis) }\end{array}$ & 2 & $1-4 /$ day & Small and firm & Continuous \\
\hline
\end{tabular}




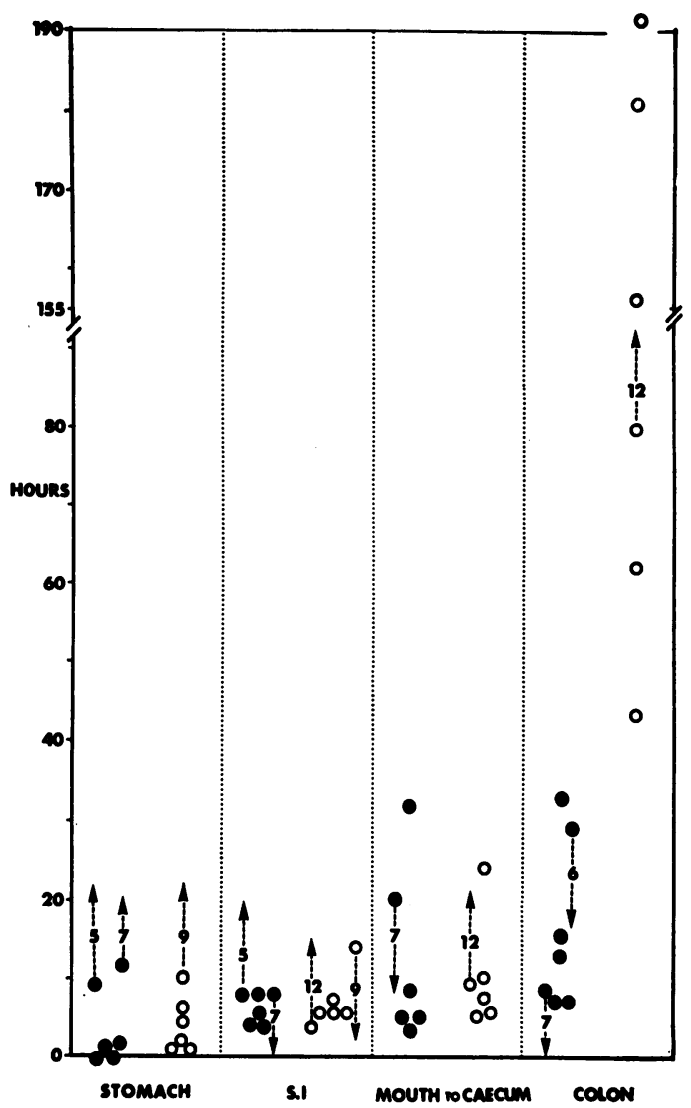

Fig 1 Transit of capsule through the stomach, small intestine, and colon and the mouth to caecum (time in hours). In one of the 13 subjects (6) colonic transit only is available as the telemetering capsule failed to transmit pressure activity after the capsule had been swallowed; localization to the colon was achieved by brief fluoroscopy. In four other patients $(5,7,9,12)$ the precise time the capsule left either the stomach or small intestine is not known as the event occurred during the night. The direction and the greatest possible error that could have occurred in these subjects is indicated by the arrows. 0 diarrhoeal subjects; $\mathrm{O}=$ constipated patients. subjects (fig 1) the mouth-to-caecal transit was known to the nearest 15 minutes, and in those it was $11.00 \pm 5.30$ hours in diarrhoea and 10.60 \pm 3.44 hours in constipation. In contrast with these observations colonic transit was faster in diarrhoea $(17.5 \pm 4 \cdot 1$ hours, range 8 to 33 hours) than in constipation (118 $\pm 4 \cdot 1$ hours, range 43 to 189 hours), and there was no overlap between the two groups (fig 1). This difference was highly significant $(P<0.01)$.

Replicate studies in four subjects showed reasonable reproducibility of the gastric and small intestinal transit times (table II).

In both diarrhoeal and constipated patients the capsule progressed through the colon by a series of discrete forward movements, which in diarrhoea occurred every few hours and usually shortly after a meal (fig 2a). In constipated subjects these movements occurred only once every 24 hours and almost always during the night in all parts of the colon except the 'sigmoid' (figs $3 a$ and $4 a$ ) but the capsule rarely remained at any one site for more than 24 to 30 hours. Retropulsive movements were recorded in only two patients (figs 4a and b), both of whom were constipated and not responsive to senna.

Movements of the capsule were not associated with the urge to defaecate. After defaecation the capsule either moved forward or remained in the same place.

It was possible to compare mouth-to-anus transit times for the capsule and the pellets in six diarrhoeal and six constipated subjects. Although the pellets tended to travel faster than the capsule in diarrhoea (table III), this difference was not significant (table III). In constipation capsule and pellet transit times were similar (table IV) and an abdominal radiograph in one constipated subject showed the capsule lying in the centre of the main bolus of pellets in the colon (fig 5).

\section{REPEAT STUDIES ON DRUG TREATMENT Senna}

Four constipated subjects were studied twice. They

\begin{tabular}{|c|c|c|c|c|c|c|c|}
\hline \multirow[t]{2}{*}{ Patient } & \multirow[t]{2}{*}{ Diagnosis } & \multicolumn{2}{|c|}{ Pill in Stomach in Hours } & \multicolumn{2}{|c|}{ Pill in Small Intestine in Hours } & \multicolumn{2}{|c|}{ Mouth to Caecum in Hours } \\
\hline & & First Study & Second Study & First Study & Second Study & First Study & Second Study \\
\hline 1 & $\begin{array}{l}\text { Postvagotomy and } \\
\text { pyloroplasty diarrhoea }\end{array}$ & 0.5 & $4 \cdot 5$ & $8 \cdot 0$ & $4 \cdot 0$ & $8 \cdot 5$ & $8 \cdot 5$ \\
\hline $\begin{array}{l}10 \\
11 \\
12\end{array}$ & $\begin{array}{l}\text { Constipation } \\
\text { Constipation } \\
\text { Irritable bowel syndrome } \\
\text { Constipation }\end{array}$ & $\begin{array}{l}4 \cdot 5 \\
0 \cdot 6 \\
6 \cdot 0\end{array}$ & $\begin{array}{l}1 \cdot 75 \\
0 \cdot 8 \\
1 \cdot 2\end{array}$ & $\begin{array}{l}5 \cdot 5 \\
5 \cdot 5 \\
>3\end{array}$ & $\begin{array}{l}4 \cdot 5 \\
2 \cdot 5 \\
>7\end{array}$ & $\begin{array}{r}10 \cdot 0 \\
6 \cdot 1 \\
9-21\end{array}$ & $\begin{array}{l}6 \cdot 25 \\
3 \cdot 1 \\
8 \cdot 2-24\end{array}$ \\
\hline
\end{tabular}

Table II Replicate gastric emptying rates and small intestinal transit times in four patients ${ }^{1}$

${ }^{1}$ Colonic data are not given as in three of the four medication was given when the capsule was in the colon. 


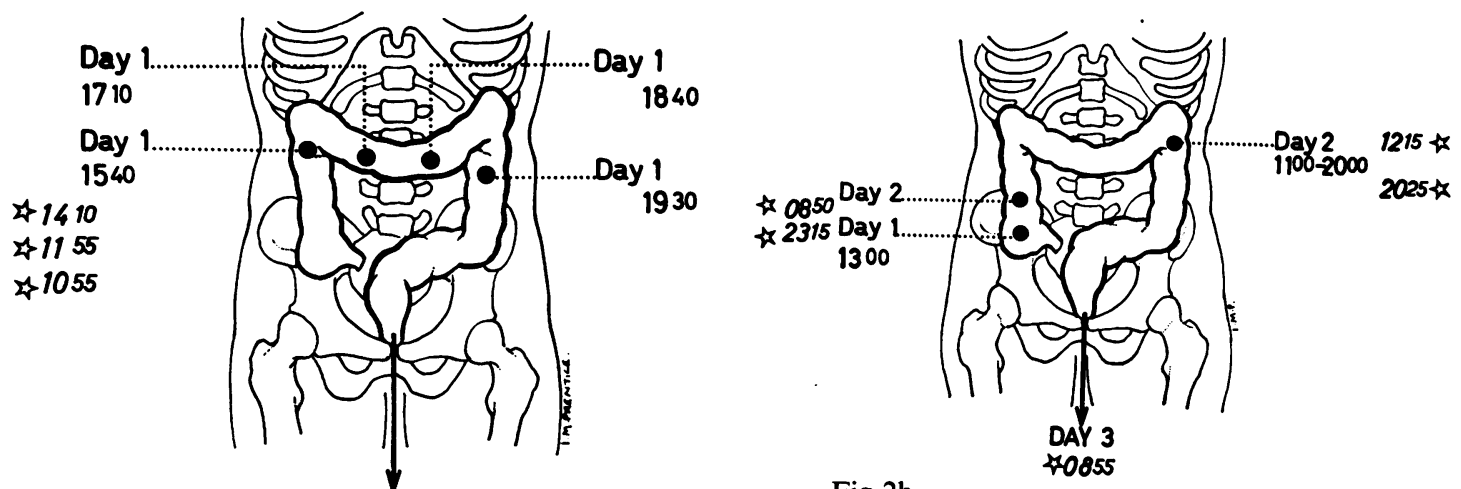

Fig 2a

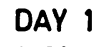

Fig $2 b$

* 2130

Fig 2 Colonic plot from a patient with diarrhoea after vagotomy and pyloroplasty: (a) when receiving no treatment and (b) on codeine $60 \mathrm{mg}$ six hourly. is = bowel actions

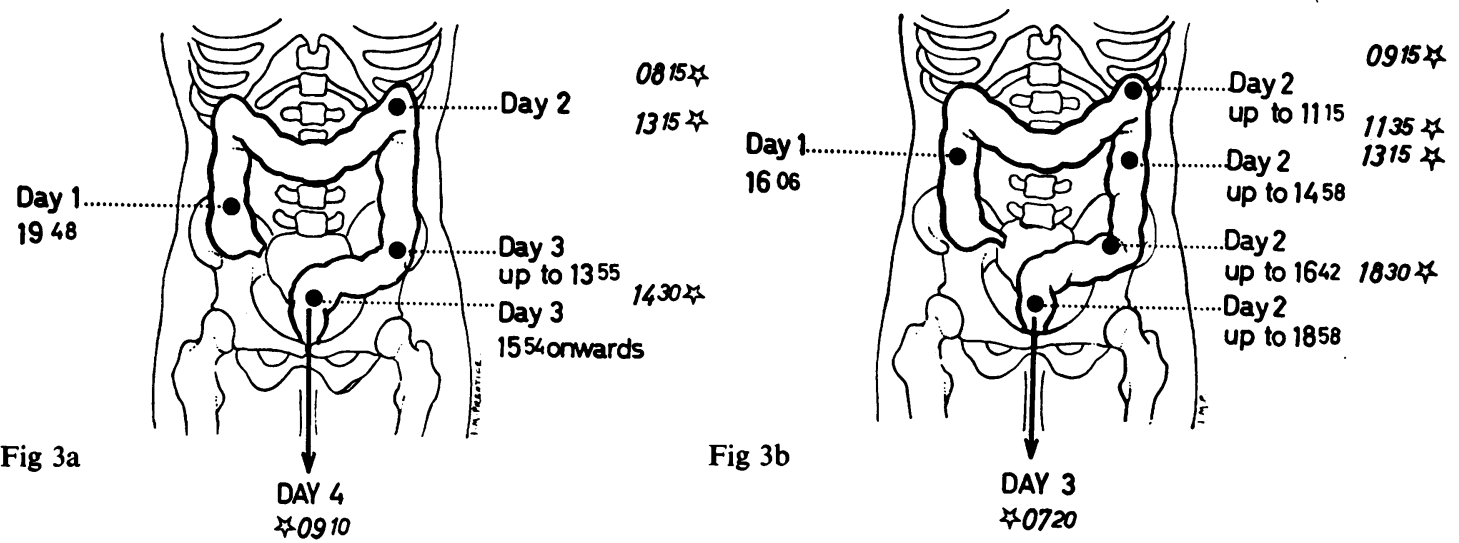

Fig 3 Colonic plot from constipated subject: (a) when not receiving treatment and (b) when given four tablets of senna at 06.00 hours on day 2 with clinical effect. $\hat{s}=$ bowel actions.

\begin{tabular}{|c|c|c|c|c|}
\hline \multirow[t]{2}{*}{ Patient } & \multicolumn{3}{|c|}{ Total Transit Time in Hours } & \multirow{2}{*}{$\begin{array}{l}\text { Capsule with } \\
\text { Largest Single } \\
\text { Elimination of } \\
\text { Pellets }\end{array}$} \\
\hline & $\begin{array}{l}50 \% \\
\text { Pellets }\end{array}$ & Capsule & $\begin{array}{l}80 \% \\
\text { Pellets }\end{array}$ & \\
\hline \multicolumn{5}{|c|}{ Diarrhoea } \\
\hline 1 & 21.5 & $21 \cdot 5$ & 48 & Yes \\
\hline 2 & $11 \cdot 5$ & 37 & 27 & No \\
\hline 3 & $4 \cdot 5$ & 11.5 & $21 \cdot 75$ & No \\
\hline 4 & \multicolumn{3}{|c|}{ No pellets given with capsule } & \\
\hline 5 & $21 \cdot 5$ & 45 & $21 \cdot 5$ & No \\
\hline 6 & $31 \cdot 5$ & 31 & 55 & No \\
\hline 7 & $12 \cdot 5$ & 17 & $12 \cdot 5$ & No \\
\hline \multicolumn{5}{|c|}{ Constipation on Senna } \\
\hline 10 & 47 & 47 & 47 & Yes \\
\hline 11 & 120 & 168 & 144 & No \\
\hline 12 & 21 & 52 & 21 & No \\
\hline
\end{tabular}

Table III Comparison of transit times measured by the capsule and radioopaque pellets in patients with diarrhoea and in constipated subjects on senna ${ }^{1}$

$250 \%$ pellets: capsule $P>0.05$. Capsule: $80 \%$ pellets $P<0.7$. $3 *$

\begin{tabular}{|c|c|c|c|c|}
\hline \multirow[t]{2}{*}{ Patient } & \multicolumn{3}{|c|}{ Total Transit Time in Hours } & \multirow{2}{*}{$\begin{array}{l}\text { Capsule with } \\
\text { Largest Single } \\
\text { Elimination of } \\
\text { Pellets }\end{array}$} \\
\hline & $\begin{array}{l}50 \% \\
\text { Pellets }\end{array}$ & Capsule & $\begin{array}{l}80 \% \\
\text { Pellets }\end{array}$ & \\
\hline \multicolumn{5}{|c|}{ Constipation } \\
\hline 8 & 164 & 164 & 184 & Yes \\
\hline 9 & 192 & 192 & - & Yes \\
\hline 10 & $94 \cdot 5$ & $72 \cdot 5$ & $94 \cdot 5$ & No \\
\hline 11 & 189 & 189 & 189 & Yes \\
\hline 12 & 92 & 92 & 107 & Yes \\
\hline 13 & 73 & 48 & 101 & Yes \\
\hline \multicolumn{5}{|c|}{ Diarrhoea on Codeine } \\
\hline 3 & 27 & $49 \cdot 0$ & $49 \cdot 0$ & No \\
\hline
\end{tabular}

Table IV Comparison of transit times measured by the capsule and by the radioopaque pellets in constipated subjects and in one diarrhoeal patient on codeine ${ }^{1}$

${ }^{150} \%$ pellets: capsule $P<0.9$. Capsule: $80 \%$ pellets $P>0.05$. 

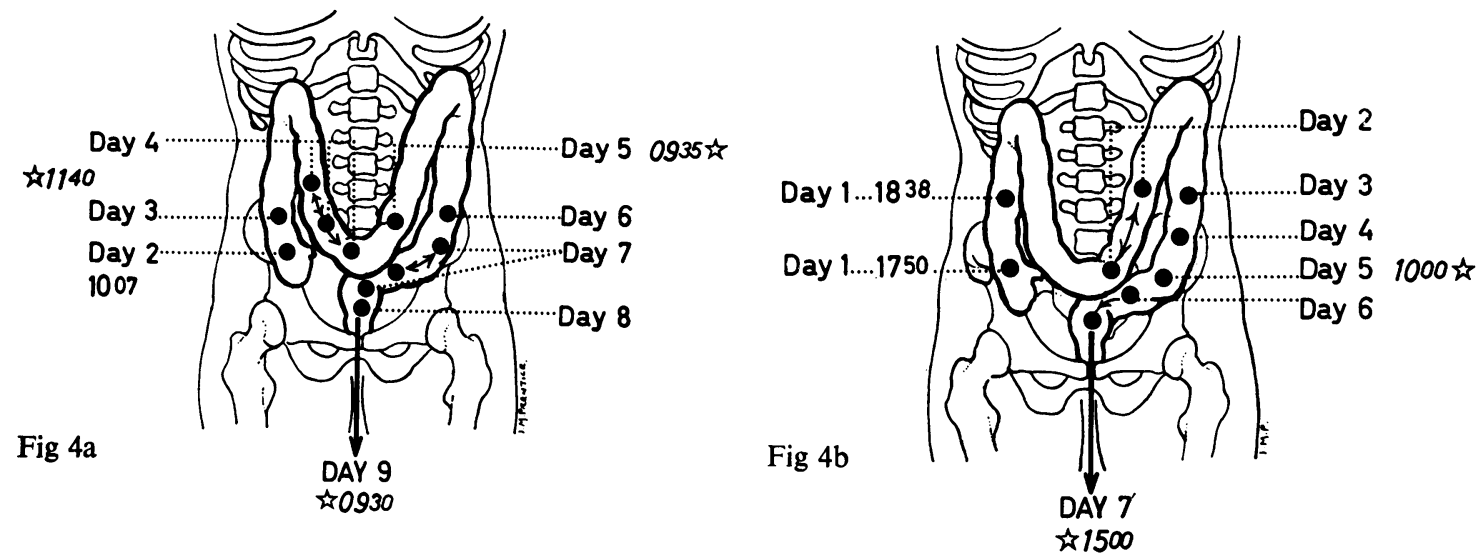

Fig 4 Colonic plot from a constipated subject: (a) when not receiving treatment and (b) when given metoclopramide $10 \mathrm{mg}$ orally before breakfast, lunch, and supper on day 1 , four tablets of senna at 06.00 hours on day 3, and a phosphate enema on day 7 . is = bowel action.

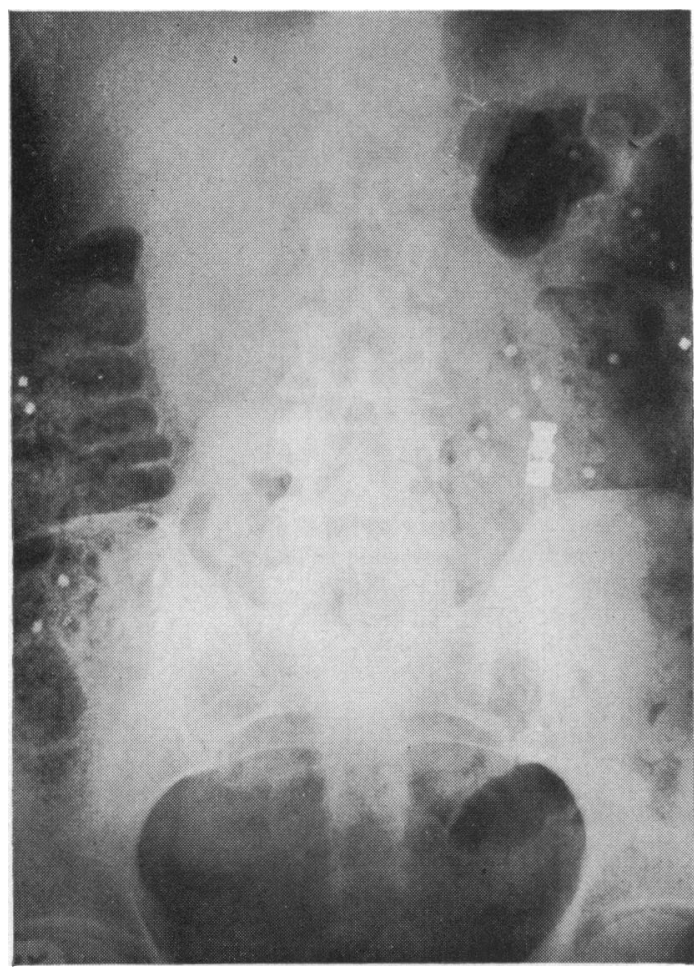

Fig 5 Radiograph showing the capsule and radioopaque pellets in the colon of a constipated patient.

received four tablets of standardized senna at 06.00 hours on the second (three patients) or third (one patient) day of the repeat test at the time when the capsule was in the colon.

In two patients senna produced several fluid bowel actions within four to eight hours of adminis- tration (fig 3b). In both patients the transit plot and elimination of the pellets and capsule resembled diarrhoeal states (table III). As in untreated subjects, movements of the capsule did not accompany or precede the urge to defaecate, although the capsule usually moved forward after defaecation. In the two other patients (fig 4b) senna did not cause movement of the capsule or bowel actions.

\section{Metoclopramide}

One constipated patient (figs $4 \mathrm{a}$ and $\mathrm{b}$ ) who was unresponsive to senna also had a prolonged gastric emptying time (10 hours) during the first study. On the first day of the second study she was given oral metoclopramide $10 \mathrm{mg}$ before breakfast, lunch, and supper. On this occasion the capsule left the stomach within 40 minutes, small intestinal transit was seven and a half hours (first study $10+$ hours) and the capsule was in the mid ascending colon within nine hours of ingestion. By 24 hours the capsule had reached the mid transverse colon (first study 96 hours). Defaecation did not, however, occur. The capsule reached the sigmoid colon by the sixth day compared with the ninth day in the first study but was not eliminated that day, although defaecation occurred.

\section{Codeine}

One diarrhoeal subject was studied for a second time while taking codeine phosphate $60 \mathrm{mg}$ six hourly (fig $2 \mathrm{~b}$, table III). Small intestinal transit was prolonged by only two hours, but the capsule remained in the colon an extra 34 hours. Propulsion of the capsule was diminished, yet the patient experienced severe urges to defaecate although he was often unable to open his bowels. 


\section{Discussion}

This paper presents an entirely new approach to the differential measurement of small and large bowel transit times in man: the method also allows frequent observations of movements of colonic contents to be made without recourse to radiographs. Although the number of patients so far investigated is small, some interesting observations on the mechanism of diarrhoea and constipation have emerged.

\section{VALIDITY OF TECHNIQUE}

The method is time-consuming but technically simple, avoids intubation, and gives much information with minimal irradiation of the ambulant patient. Transit times might be influenced by specific gravity of the marker (Hoelzel, 1930), but for several reasons it seems likely that the capsule travels with the main bulk of the meal. The gastric emptying time of the capsule is similar to the gastric half life of an isotopically labelled meal (Griffith, Owen, Campbell, and Shields, 1968; Harvey, Mackie, Keeling, and Davies, 1970), whilst the mouth-tocaecal transit of the capsule closely resembles mouth-to-stoma transit of radioopaque pellets in healthy ileostomists (Waller, 1975). Moreover, total transit times measured simultaneously with the capsule (SG 1.60-1.87) and radioopaque pellets (SG 1.06) do not differ significantly and radiographs show that the capsule travels with the main bolus of pellets in the colon (Holdstock et al, 1970; present study). However, the consistency of gastrointestinal contents may influence the behaviour of markers. In diarrhoea and after senna there was a definite, but not significant, tendency for the pellets to arrive ahead of the capsule, whilst in constipation the capsule tended to travel faster than the pellets. Such streaming of bowel contents has been reported recently with chemical markers of fluid and solid phases of faeces (Findlay, Mitchell, Anderson, Eastwood, and Smith, 1974). However, the capsule does not measure transit of the fluid phase of meals, which leaves the stomach more rapidly than the solid phase (Heading, Tothill, Laidlaw, and Shearman, 1971).

MECHANISMS OF DIARRHOEA AND CONSTIPATION

Gastric emptying and small intestinal transit time were similar in diarrhoea and constipation, but colonic transit was significantly more rapid in diarrhoea, whatever the aetiology. Other workers using different techniques have also failed to find decreased small intestinal transit times in diarrhoeal states (Andrysek, Šetka, Georgi, Gütz, Altenbrunn, and Berndt, 1966; Cummings, Newman, Misiewicz, Milton-Thompson, and Billings, 1973; Cummings, Milton-Thompson, Billings, Newman and Misiewicz, 1974; Mize, Wu, and Whalen, 1974). This raises the question of the relationship between flow rates and transit in various parts of the gut. In diarrhoea associated with increased fluid secretion into the small bowel lumen produced by prostaglandin $\mathrm{F}_{2 \alpha}$ or $\mathrm{E}_{2}$ increased small intestinal flow rates were not accompanied by accelerated transit (Cummings et al, 1973; 1974; Mize et al, 1974). Although routine barium meals have suggested that small intestinal transit time is more rapid in diarrhoeal states (Kalser, Zion, and Bockus, 1956) accelerated transit is rarely seen if the barium is given with a standard test meal (Mattsson, Perman, and Lagerlöf, 1960). Even if small intestinal transit is decreased, diarrhoea does not necessarily follow; for example, it is not produced by metoclopramide (Margiesson, Sorbey, and Williams, 1966; James and Hume, 1968; Kreel, 1970).

By contrast, the present observations show that fast colonic transit is a striking feature of diarrhoea. Other studies also suggest that faecal weight is largely determined by large bowel function, because it is increased by colonic, rather than small intestinal, resection (Cummings, James, and Wiggins, 1973). Fast colonic transit could be initiated by an abnormally high ileal output causing overdistension of the caecum or by an abnormal response of the colon to the distending stimulus.

In both diarrhoea and constipation colonic contents travelled by a series of discontinuous forward movements, which occurred every few hours in diarrhoea. Twenty-four hours or longer elapsed between movements in constipation. Because defaecation in constipated subjects occurred less frequently than propulsion, it seems likely that the faeces were slowly packed into the distal colon. This finding lends support to the hypothesis that a luminal carcinogen may be responsible for distal colonic cancer (Aries, Crowther, Drasar, Hill, and Williams, 1969; Burkitt, 1971).

No correlation between the movements of colonic contents and the urge to defaecate has been found in this study. In diarrhoeal subjects or after senna, extensive propulsive movements were not followed by the urge to defaecate and the capsule did not necessarily move forward with defaecation.

The present results suggest that further studies with this technique are likely to improve the understanding of the mechanisms underlying normal and abnormal bowel function and the action of drugs on the gut.

The author thanks Dr T. Smith (now at the Clinical 
Research Centre, Northwick Park Hospital) for designing and making the hand-held scintillation counter and for technical advice, Mr R. Sapsford, technician MRC Gastroenterology Unit, for technical assistance, and Miss Nancy Kiley, BSc, and Mrs Anne Wilkins, BSc, technicians, MRC Gastroenterology Unit, for much help in charting capsule movements. The author also thanks Dr J. J.Misiewicz for helpful criticism, Mrs I. M. Prentice, AMAA, and $\mathrm{Mr}$ A. G. Booker, FPI, medical artist and medical photographer, Central Middlesex Hospital, for the figures, and Mrs P. Evans for typing the manuscript.

\section{References}

Alvarez, W. C., and Freedlander, B. L. (1924). The rate of progress of food residues through the bowel. J. Amer. med. Ass., 83, 576-580.

Andrysek, O., Štka, J., Georgi, P., Gütz, H. J., Altenbrunn, J., and Berndt, H. (1966). Passage of ${ }^{198} \mathrm{Au}$ through the small intestine. Rev. Czech. Med., 12, 225-229.

Aries, V., Crowther, J. S., Drasar, B. S., Hill, M. J., and Williams, R. E. O. (1969). Bacteria and the aetiology of cancer of the large bowel. Gut, 10, 334-335.

Burkitt, D. P. (1971). Epidemiology of cancer of the colon and rectum. Cancer (Philad.), 28, 3-13.

Connell, A. M., McCall, J., Misiewicz, J. J., and Rowlands, E. N. (1963). Observations on the clinical use of radiopills. Brit. med. J., 2, 771-774.

Cummings, J. H., James, W. P. T., and Wiggins, H. S. (1973). Role of the colon in ileal-resection diarrhoea. Lancet, 1, 344-347.

Cummings, J. H., Milton-Thompson, G. S., Billings, J. A., Newman, A., and Misiewicz, J. J. (1974). Studies on the site of production of diarrhoea induced by prostaglandins. (Abstr.) Clin. Sci. 46, $15 P$.

Cummings, J. H., Newman, A., Misiewicz, J. J., Milton-Thompson, G. S., and Billings, J. A. (1973). Effects of intravenous prostaglandin $\mathrm{F}_{2} \alpha$ on small intestinal function in man. Nature (Lond.), 243, 169-171.

Findlay, J. M., Mitchell, W. D., Anderson, A. J. B., Eastwood, M. A. and Smith, A. N. (1973). Faecal flow patterns in cholorrheic enteropathy and colonic diverticular disease. In Proceedings of the 4th International Symposium on Gastro-intestinal Motility, edited by E. E. Daniels, pp. 355-364. Mitchell Press, Vancouver.
Griffith, G. H., Owen, G. M., Campbell, H., and Shields, R. (1968). Gastric emptying in health and in gastroduodenal disease. Gastroenterology, 54, 1-7.

Harvey, R. F., Mackie, D. B., Brown, N. J. G., Keeling, D. H., and Davies, W. T. (1970). Measurement of gastric emptying time with a gamma camera. Lancet, 1, 16-18.

Heading, R. C., Tothill, P., Laidlaw, A. J., and Shearman, J. C. (1971). An evaluation of ${ }^{113}$ indium DTPA chelate in the measurement of gastric emptying by scintiscanning. Gut, 12, 611-615.

Hinton, J. M., Lennard-Jones, J. E., and Young, A. C. (1969). A new method for studying gut transit times using radio-opaque markers. Gut, 10, 842-847.

Hoelzel, F. (1930). The rate of passage of inert materials through the digestive tract. Amer. J. Physiol., 92, 466-497.

Holdstock, D. J., Misiewicz, J. J., Smith, T., and Rowlands, E. N. (1970). Propulsion (mass movements) in the human colon and its relationship to meals and somatic activity. Gut, 11, 91-99.

James, W. B., and Hume, R. (1966). Action of metoclopramide on gastric emptying and small bowel transit time. Gut, 9, 203-205.

Kalser, M. H., Zion, D. E., and Bockus, H. L. (1956). Functional diarrhea: an analysis of the clinical and roentgen manifestations Gastroenterology, 31, 629-648.

Kreel, L. (1970). The use of oral metoclopramide in the barium meal and follow-through examination. Brit. J. Radiol., 43, 31-35.

Margieson, G. R., Sorby, W. A., and Williams, H. B. L. (1966). The action of 'Metoclopramide' on gastric emptying: a radiological assessment. Med.J. Aust., 2, 1272-1274.

Mattsson, O., Perman, G., and Lagerlöf, H. (1960). The small intestine transit time with a physiologic contrast medium Acta radiol. (Stockh.), 54, 334-344.

Misiewicz, J. J., Waller, S. L. and Eisner M. (1966). Motor responses of human gastrointestinal tract to 5-hydroxy tryptamine in vivo and in vitro. Gut 7, 208-216.

Misiewicz, J. J., Waller, S. L., Fox, R. H., Goldsmith, R., and Hunt, T. J. (1968). The effect of elevated body temperature and of stress on the motility of stomach and colon in man. Clin. Sci. 34, 149-159.

Misiewicz, J. J., Waller, S. L., Kiley, Nancy and Horton, E. W. (1969). Effect of oral prostaglandin $E_{1}$ on intestinal transit in man. Lancet, 1, 648-651.

Mize, B. F., Wu, W. C., and Whalen, G. E. (1974). The effect of prostaglandin $\mathrm{E}_{2}\left(\mathrm{PGE}_{2}\right)$ on net jejunal transport and mean transit time (Abstr.). In Proceedings of the 5th World Congress of Gastroenterology, Mexico City, 1974, p. 237.

Rowlands, E. N., and Wolff, H. S. (1960). Telemetering from the digestive tract. Brit. Commun. Electron., 7, 598-601.

Waller, S. L. (1975). The effect of codeine on mouth to stoma transit times in patients with ileostomies. (In preparation).

Waller, S. L., and Misiewicz, J. J. (1969). Prognosis in the irritable bowel syndrome: a prospective study. Lancet, 2, 753-756. 